\title{
THE IMPACTS OF TEMPORARY BUT ANTICIPATED TOURISM SPENDING: AN APPLICATION TO THE GLASGOW 2014 COMMONWEALTH GAMES
}

\author{
Grant J. Allan¹, Patrizio Lecca and Kim Swales \\ Fraser of Allander Institute, Department of Economics, University of Strathclyde, Glasgow
}

\begin{abstract}
An extensive literature attempts to identify the economic impact of tourism expenditure. While Input-Output methods have been widely applied these may not always be appropriate for such applications and there is a growing use of more flexible Computable General Equilibrium (CGE) approaches. This paper uses a multi-period Scottish CGE model to estimate the system-wide effects of the temporary tourism expenditure related to the Glasgow 2014 Commonwealth Games. We quantify the sensitivity of our results to model specification, focusing in particular on how investment and consumption decisions are made and shifted over time to accommodate the temporary tourism shock. As part of this analysis we identify the pre-announcement period that optimises the present value of the economic impact. Whilst the empirical results apply to a specific event, our results have implications for similar analyses applied to mega events and other temporary phenomena affecting tourism expenditure, such as terrorism attacks or epidemics.
\end{abstract}

Key words: economic impact, CGE modelling, mega-events

JEL classifications: C68, L83, R11 and R13.

Acknowledgements: The authors are very grateful for the helpful comments of two anonymous referees and participants at the Workshop for Regional Development, University of Strathclyde, Glasgow, January 2014; Annual Conference, Regional Science Association, British and Irish Section, Aberystwyth, August 2014: Annual Conference, North American Regional Science Council, Washington, November 2014 and the Third IPTS Regional Modelling Workshop, Seville, December 2014, for valuable comments on earlier versions of this paper.

\footnotetext{
${ }^{1}$ Grant Allan is a Lecturer, Patrizio Lecca is a Research Fellow and Kim Swales is an Emeritus Professor in the Fraser of Allander Institute, Department of Economics, University of Strathclyde, 130 Rottenrow, Glasgow, UK. Allan is the corresponding author (Email: grant.j.allan@strath.ac.uk Tel: (+44) 1415483838 ) is research interests include regional economic modelling, energy economics and sports economics. Lecca's research is in the field of economic modelling and devolution. Swales' research is in regional economic analysis and modelling.
} 


\section{Abstract}

An extensive literature attempts to identify the economic impact of tourism expenditure. While Input-Output methods have been widely applied these may not always be appropriate for such applications and there is a growing use of more flexible Computable General Equilibrium (CGE) approaches. This paper uses a multi-period Scottish CGE model to estimate the system-wide effects of the temporary tourism expenditure related to the Glasgow 2014 Commonwealth Games. We quantify the sensitivity of our results to model specification, focusing in particular on how investment and consumption decisions are made and shifted over time to accommodate the temporary tourism shock. As part of this analysis we identify the pre-announcement period that optimises the present value of the economic impact. Whilst the empirical results apply to a specific event, our results have implications for similar analyses applied to mega events and other temporary phenomena affecting tourism expenditure, such as terrorism attacks or epidemics.

Key words: economic impact, CGE modelling, mega-events

JEL classifications: C68, L83, R11 and R13. 


\section{Introduction}

An extensive literature attempts to identify the full local economic impact of tourism expenditure. Any local economic development agency that is considering the encouragement of tourism as an element of its development strategy, or has an economy already heavily dependent on tourism, requires accurate information on these effects. The existing studies typically use conventional demand-driven Keynesian, Input-Output (IO) or Social Accounting Matrix multipliers to quantify the full supply chain (indirect) and linked consumption (induced) effects associate with the tourist spending (e.g. Lee and Taylor, 2005; Incera and Fernández, 2015). ${ }^{2}$ These standard multipliers assume that no supply-side constraints operate in the local economy (Miller and Blair, 2009). This implies that there are no locally scarce resources that are bid away from other uses if tourism expenditure increases or are released for other uses if tourist spending falls.

This assumption of passive supply is acceptable for long-run analysis because local economies are typically open to the free migration of labour and capital (McGregor et al. 1996). Therefore in the long run, production capacity and the labour supply can more fully adjust to changes in local demand. The conventional multiplier approach is therefore appropriate for identifying the ultimate year-on-year impact of a permanent tourist attraction or the effect of regular and frequent tourism events. However, for temporary tourism demand shocks, such as those associated with SARS, political conflicts, terrorist attacks and mega events, the short-run crowding out or the release of local resources become important determinants of the overall economic outcome. In this setting, Computable General Equilibrium (CGE) analysis has typically been favoured (e.g. Dwyer et al, 2004).

This paper focuses on one type of temporary shock, the hosting of a mega event. These are one-off events, such as the Olympic Games, the World Cup or the European City of Culture, which generate large temporary tourist inflows accompanying by increased tourism

\footnotetext{
${ }^{2}$ More examples are given in Section 3.
} 
expenditure. Mega events have a number of characteristics that make them particularly appropriate subjects of study. First, the timing and duration of the event are known with some precision, together with the likely direct impact on tourism numbers and expenditures. Second, these events are typically announced well in advance. Third, one element of the justification for cities and regions bidding for such events is their potential positive economic impact, so that ex ante accurate economic appraisal is required for effective policy implementation.

The hosting of the Commonwealth Games in Glasgow in 2014 resulted in an estimated $£ 100$ million temporary tourism expenditure injection to the Scottish economy (TNS et al, 2014). This paper has three main aims. The first is to use a multi-period CGE model of the Scottish economy to generate the best estimate of the system-wide effects of this expenditure on the Scottish economy. The second is to quantify the sensitivity of this result to the way in which investment and consumption decisions are made and the extent to which these expenditures are shifted over time to accommodate the temporary shock. The third is to identify the preannouncement period that optimises the present value of the economic impact. Whilst the empirical results apply to a specific mega event, the paper also discusses their implications for similar analysis applied to other mega events and other temporary phenomena, such as terrorism attacks or epidemics.

The paper proceeds as follows. Section 2 quantifies the specific tourism expenditure related to the Glasgow 2014 Commonwealth Games. Section 3 reviews the application of InputOutput, Social Accounting Matrix and Computable General Equilibrium models to the analysis of tourism expenditure in general and that expenditure linked to major events in particular. Section 4 outlines the nature of the model used in the present paper and Section 5 details the simulation strategy adopted. Section 6 presents the simulation results not only from the central model but also a range of backward and forward-looking specifications with varying degrees of pre-announcement and factor supply assumptions. We are particularly interested in revealing the alternative cumulative results on key economic variables, as well as the timing 
of these results under each specification. Section 7 investigates the economic impact of varying the degree of pre-announcement and the policy implications. Section 8 concludes.

\section{The Tourism Expenditure Shock}

The Commonwealth Games are a multi-sport event held every four years, with cities across the Commonwealth bidding for the right to host them. The first Games, held in 1930, had 400 competitors representing 11 nations whilst at the Glasgow 2014 Games there were almost 5,000 competitors, from 71 nations. ${ }^{3}$ Using the number of participating athletes as a metric, the scale of the Glasgow 2014 Games falls between the London 2012 Summer and Sochi 2014 Winter Olympics.

Research funded by the Scottish Government, Glasgow City Council, Glasgow Life and Glasgow City Marketing Bureau estimates that over the period of the Glasgow 2014 Commonwealth Games, Glasgow hosted 690,000 visitors, of which 440,000 were "day visitors" (i.e. those who did not stay overnight) and 250,000 stayed at least one night ("overnight visitors") (TNS et al, 2014). This and additional information from that report is presented in Table 1. The same source states that $98 \%$ of the day and $18 \%$ of the overnight visitors were Scottish residents, so that there were 8,800 non-Scottish day and 205,000 nonScottish overnight visitors. This paper focuses on the economic impact of the expenditure made by these non-Scottish tourists.

The day visitors made on average 2.6 trips to the Games and their tourism expenditure on each trip averaged $£ 57$; overnight visitors stayed on average 6.8 days and with a tourism expenditure of $£ 125$ a day. Given the information shown in Table 1, we estimate the total expenditure in Scotland by non-Scottish visitors to the city as $f 175.5$ million. This is calculated

\footnotetext{
${ }^{3}$ At their inception they were called the British Empire Games but were renamed the Commonwealth Games in 1978.
} 
on the assumption that in each category ("day" and "overnight" visitor) the average spending by a Scottish and non-Scottish tourist is the same.

These gross expenditures are allocated across the sectors in accordance with the base year distribution of tourism demand in the most recent (2009) Scottish Input-Output accounts. The expenditures on Scottish goods and services are then calculated at basic prices by removing imports and net taxes/margins from the gross expenditures figure. ${ }^{4}$ These adjustments mean that the total expenditure on Scottish goods and services made by international tourists is precisely $f 100$ million. This is the exogenous demand shock that we enter into the model in all simulations.

Table 1: The number and expenditures of non-Scottish visitors associated with the Glasgow 2014 Commonwealth Games

\begin{tabular}{|c|c|c|c|c|c|c|}
\hline \multirow[t]{2}{*}{$\begin{array}{l}\text { Visitor } \\
\text { type }\end{array}$} & \multicolumn{2}{|c|}{$\begin{array}{l}\text { Visitor Numbers } \\
\qquad(, 000 \mathrm{~s})\end{array}$} & \multirow[t]{2}{*}{$\begin{array}{l}\text { Average } \\
\text { trips/days }\end{array}$} & \multirow[t]{2}{*}{$\begin{array}{l}\text { Expenditure per } \\
\text { trip/day }(f)\end{array}$} & \multicolumn{2}{|c|}{$\begin{array}{l}\text { Expenditure by non-Scottish } \\
\text { visitors ( } \mathrm{f} \text { million) }\end{array}$} \\
\hline & Total & $\begin{array}{l}\text { Non- } \\
\text { Scottish }\end{array}$ & & & Total & $\begin{array}{l}\text { Total Scottish } \\
\text { goods \& services }\end{array}$ \\
\hline Day & 440 & 8.8 & 2.6 & 57 & 1.3 & 0.7 \\
\hline Overnight & 250 & 205 & 6.8 & 125 & 174.2 & 99.3 \\
\hline
\end{tabular}

Source: TNS et al. (2014)

The expenditure injection from non-resident tourists is not the only direct Scottish economic impact generated by the 2014 Commonwealth Games. Therefore in restricting the direct impacts to the 2014 increased expenditure by non-Scottish tourists, the simulation results reported in Sections 6 and 7 are likely to systematically underestimate the full impact of the Commonwealth Games on the Scottish economy. However, the analysis focusses solely on the 2014 tourism expenditures by non-Scottish residents for two inter-related reasons. First,

\footnotetext{
${ }^{4}$ Net taxes, margins and imports from the rest of the UK and the rest of the world make up $43 \%$ of the tourist expenditure.
} 
a central concern of this paper is the sensitivity of the economic outcomes to variations in the assumptions about adjustments to temporary shocks. This is illustrated most clearly where the initial shock is unambiguous and temporally distinct. Second, in the case of Commonwealth Games, the impact of other effects is likely to be small and uncertain. The tourist expenditure by Scottish residents is essentially consumption expenditure switching and will have a very small net effect (Allan et al. 2007). Similarly, much of the expenditure on venues and the Games organisation is funded by the Scottish Government which has a fixed budget. Therefore these expenditures on the Commonwealth Games simply replace similar expenditures that would have been made by the public sector. Finally supply-side and potential future tourist expenditure are uncertain and are typically given second-order importance in studies of mega events. ${ }^{5}$

\section{Literature review: multi-sectoral modelling of tourism impacts}

There is a growing academic literature that uses multi-sectoral modelling techniques to explore the impact of tourism expenditure associated with mega sporting events. InputOutput analysis is particularly well-suited to modelling the impact of exogenous expenditure injections on an economy, where the initial demand stimulus generates subsequent increased production through linked intermediate ("indirect") demand and increased ("induced") household consumption (Miller and Blair, 2009). It provides estimates of the aggregate impact of a demand shock on measures of economic activity such as total output, employment and value added, together with the distribution of these impacts across different sectors of the economy. The relative ease of availability of the requirements for 10 modelling - an appropriate set of expenditures for the event in question and IO accounts for the region or nation within which the event is located - has led to these techniques being widely applied in the exploration of tourism impacts (Burgan and Mules, 1992; Fletcher, 1989; Gartner and Holecek, 1983). As a specific example, Lee and Taylor (2005) employ a

\footnotetext{
${ }^{5}$ There could also be other linked demand-side impacts For example, Rose and Spiegel (2011) find evidence that hosting, or even simply bidding for, an Olympic Games has a positive impact on the nation's subsequent exports. Further, Fourie and Santego-Gallego (2011) find econometric evidence that hosts of mega events experience some additional tourism prior, though not subsequent, to the event.
} 
survey to gather data on expenditures by foreign tourists visiting South Korea for the 2002 football World Cup. The introduction of these exogenous expenditure disturbances into an IO model for South Korea, generates figures for the total (aggregate) impact of the expenditures made by these "World Cup tourists".

IO accounts show the linkages within an economy between production, consumption and other elements of final demand, such as exports (including tourism), investment and government expenditure. A Social Accounting Matrix (SAM) typically extends these accounts to incorporate information on other financial flows and transfers, including those involving the corporate, household and foreign sectors (Round, 2003). The SAM framework should provide a more accurate model of endogenous consumption behaviour than 10 because it provides a fuller representation of household income sources. In a similar way to IO accounts, SAMs can be used to model the consequences of demand disturbances (Daniels et al, 2004; Wagner, 1997) and have recently also been used to understand the economic impact of tourism expenditures (Ali Akkemik, 2012, Incera and Fernandez, 2015). Aside from modelling of events, IO and SAM accounts have also been used to analyse local and international linkages for the tourism sectors (Romero and Tejeda, 2011) and for the attribution of economic or environmental variables to tourism spending, (Cazcarro et al, 2014; Munday et al 2013).

Conventional IO and SAM modelling share a set of assumptions which have led to criticism of their use in the analysis of the impact of tourism expenditure. First, both types of model explicitly assume that the economy faces no supply constraints: there is excess capacity in all industrial sectors and there is unemployed labour at the existing wage. A demand (expenditure) injection has therefore no impact on relative prices and industries supplying intermediate inputs adjust in a linear fashion. That is to say, a $10 \%$ increase in demand for a sector's products generates a $10 \%$ increase in the output and employment in that sector.

Second, IO and SAM models are acknowledged to be particularly limited in assessing the timing of impacts. Conventionally, these models are interpreted as producing impacts which 
are contemporaneous with the initial injection (Miller and Blair, 2009, p. 653). This has two implications. First, all the adjustments - all the rounds of indirect and induced changes in intermediate and consumption demands - are assumed to occur in the period in which the exogenous demand disturbance occurs. Second, even anticipated expenditures only have impacts in the period in which they are made and have no impacts in previous or subsequent periods.

These central characteristics mean that IO and SAM models are not always well-suited for studying the impact of tourism expenditure and Computable General Equilibrium (CGE) methods are typically more appropriate (e.g. Dwyer et al., 2004, 2006). CGE analysis is based around the SAM accounts, so that it retains the sectoral disaggregation of the IO and SAM approaches. However, CGE models also recognise that labour and capital resources are typically scarce and therefore incorporate a more fully-developed supply side to the economy. For example, Zhou et al (1997) model the impact of a $10 \%$ reduction in visitor expenditures in Hawaii. They show that 10 overestimates the economic contraction relative to a CGE analysis. This is because in the CGE model price effects partially alleviate the fall in tourism demand through stimulating additional exports. Furthermore, it is also possible to develop dynamic CGE models where population and investment are endogenous so that factor supplies evolve along a particular time path (Giesecke and Madden, 2011). Again this is an advantage when set against 10 and SAM approaches that are more limited in their treatment of the timing of impacts.

There has been a significant growth in the use of CGE models for determining the economic impact of mega-events. For instance, for the 2008 and 2012 Olympic Games respectively, Li et al. (2013) use a CGE model ex post to quantify the local impact of international tourism expenditures in Beijing and Blake (2005) adopts a similar model to produce ex ante estimates of the impact of all expenditures in London. ${ }^{6}$ Giesecke and Madden (2011) examine the impact of the 2000 Olympics in Sydney, Australia. They contrast their historical CGE results to the earlier 10 estimates which found unambiguously positive impacts. The CGE analysis

\footnotetext{
${ }^{6} \mathrm{Li}$ and Blake (2009) also examine the effect of other (non-tourism) expenditure related to staging the Beijing Olympics such as stadia and transport infrastructure.
} 
suggests that the Olympics had a positive impact only on New South Wales, the state hosting the Games, generating a negative impact on Australia as a whole. For the 2010 World Cup, two papers by Bohlmann and Van Heerden $(2005,2008)$ use CGE modelling to identify separately first the scale and timing of the impact of the pre-event infrastructure and construction expenditures and then the event, post-event and tourism impacts on the South African economy.

Other CGE applications have studied unanticipated events that have had a major impact on tourism spending. Blake and Sinclair (2003) examines the consequences for the US economy of the rapid downturn in tourism following the September $11^{\text {th }}$ attack on the World Trade Centre in New York in 2001, and the partially mitigating consequences of the subsequent policy response. Similarly, Blake et al (2003) models the impact of the temporary changes in tourism demand following the Foot and Mouth outbreak in UK agriculture in 2001. The paper introduces changes in tourism demand for the 4 years between 2001 and 2004, with results given for each of these years. The paper does not state whether agents are aware that the negative tourism demand disturbances are temporary and, if so, how that influences their behaviour. Also the paper provides no results for the years following 2004, which would have been helpful in understanding the long-term consequences of these disturbances. Blake et al (2006) and Yeoman et al (2007) combine CGE analysis with econometric and scenario planning methods respectively to quantify the impact of exogenous future shocks occurring in the world economy on Scottish tourism expenditure and subsequent Scottish GDP and employment.

The present paper analyses the one-off temporary tourism demand disturbance - as described in Section 2 - using a CGE model of the Scottish economy. Simulations are performed with alternative specifications for agent behaviour, including whether expectations are forward-looking or not, and the degree of preannouncement. In Section 6 the results are compared with standard 10 estimates. This is of direct practical value because major sporting or cultural events are typically announced well in advance. For example, in September 2013 Tokyo won the right to host the 2020 Olympics, while the hosts of the 2018 and 2022 FIFA (football) World Cup were announced in December 2010. For the 2014 Commonwealth Games in Glasgow, the mega-event under consideration here, the location 
was announced in 2007 , so that there was a 7-year pre-announcement period. As argued earlier, using a CGE model introduces supply-side constraints which increase the realism of the estimates. However, preannouncement allows agents to relax some of these constraints, so that the appropriate modelling of forward-looking behaviour is highly relevant.

Additionally, there are likely to be impacts that predate the temporary increased tourism expenditure directly associated with a mega-event. These reflect the forward movement of investment expenditure to meet the increase in tourism demand and the consumption shifting behaviour around the period of the event. Further, hosting an event is likely to produce legacy effects in the form of additional capacity which remains after the event itself. For this reason, a forward-looking CGE model in which simulation results can be reported on a period-by-period basis is a particularly valuable modelling approach.

Blake (2005) uses a forward-looking CGE model to assess the impact of tourism spending. However, to our knowledge, the only paper which investigates the question of preannouncement is Blake (2009), which simulates the impact of a one-year, $f 1$ billion foreign tourism stimulus to the UK economy. It employs both backward- and forward-looking variants of the model, with and without preannouncement. As we argue in Section 6, our results differ markedly from those reported in Blake (2009), generating diametrically opposite policy prescriptions.

\section{Model}

AMOS is a single-region (stand-alone) CGE modelling framework. ${ }^{7}$ In this application it is parameterised using data from the Social Accounting Matrix (SAM) for Scotland for 2009 built around the IO accounts for the same year produced by the Scottish Government (2013). This section provides a very brief overview of the model. The information in the text is presented more formally in Appendix B. Greater detail is available in Lecca et al. (2013).

\footnotetext{
${ }^{7}$ AMOS is an acronym for A Macro-micro model Of Scotland.
} 
In the present case, AMOS has twenty five commodities/sectors, which are listed in Table A1 in Appendix A. The model has three domestic institutional groups - households, government and corporations - and two exogenous transactors - the rest of the UK (RUK) and the rest of the world (ROW). Commodity markets are assumed to be competitive. Financial flows are not explicitly modelled but it is assumed that the interest rate is exogenous to the model.

All simulations are run in a multi-period setting. The periods are interpreted as years, given that annual data have been used both for the benchmark SAM dataset and for parameterising behavioural relationships. The model is assumed to begin in steady-state equilibrium. This implies that with no exogenous disturbances the initial values are replicated over all subsequent time periods. After the tourism expenditure shock, long-run equilibrium is achieved when all markets are fully adjusted. In this application this occurs where the returns to capital are equalised across all sectors. Since the disturbances in the simulations are temporary and we assume no hysteresis effects, in in the long run the economy returns to the initial steady-state in all simulations reported here.

We are particularly concerned with the timing of economic impacts under temporary and anticipated demand shocks. Therefore a key feature of the model is the nature and timing of investment and consumption decisions in alternative versions of the model. However, we begin by describing the sectoral production structure which is common to all model specifications. We then examine the dynamics embedded in the different variants of the model.

The production structure for each sector is given in Figure 1 which shows how inputs are combined to generate sectoral output. Producers are assumed to minimise costs using a nested multi-level production function. Gross output is given by a constant elasticity of substitution (CES) combination of value added and intermediate inputs (Arrow et al., 1961). Labour and capital combine in a CES production function to produce value added. Intermediate goods can be either produced locally or imported, with imported goods 
imperfect substitutes for domestically produced items (Armington, 1969). With CES at all levels of the production hierarchy, in each sector the use of inputs is sensitive to changes in their relative prices.

Figure 1: The production structure in the AMOS Model

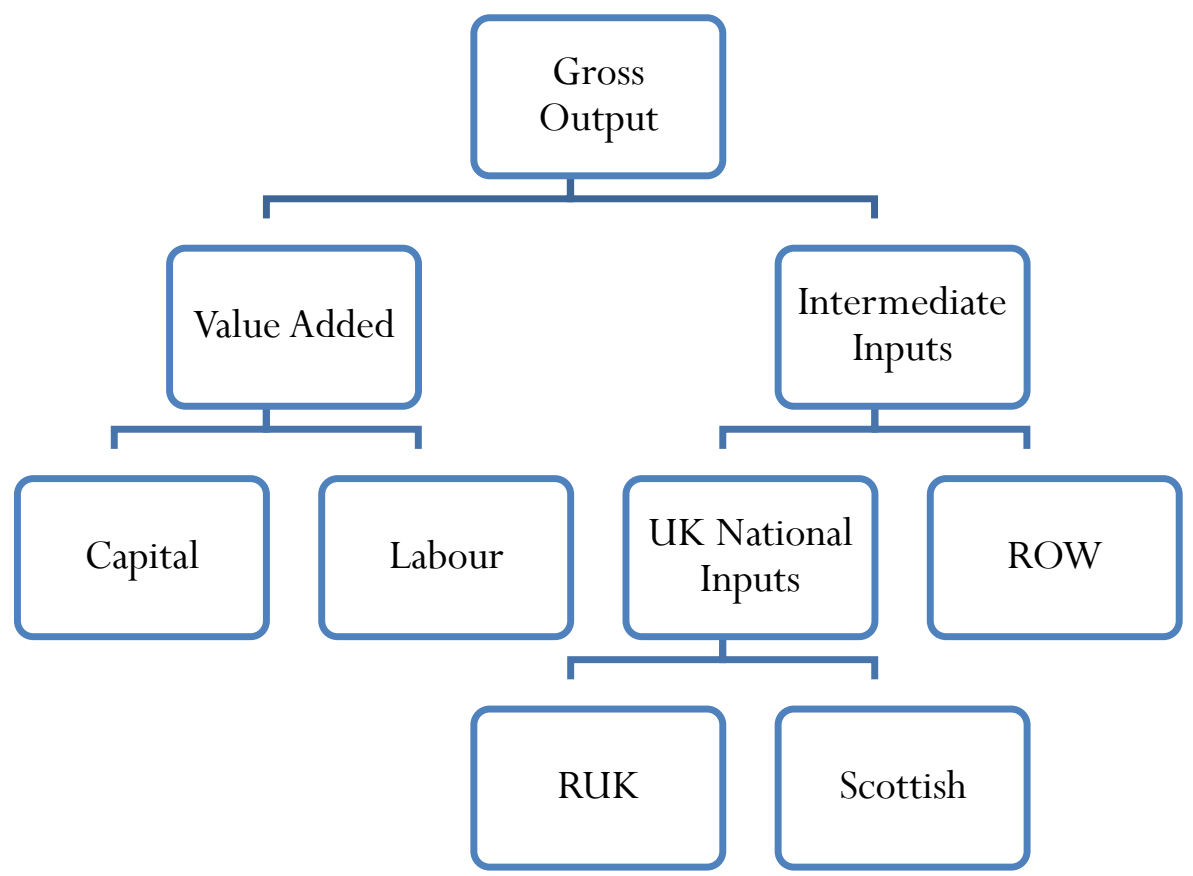

There are four components of final demand: household consumption, investment, government expenditure and exports. In all versions of the model used here, government expenditure remains constant in real terms while exports are determined by exogenous demand, together with the terms of trade and the export price elasticity. Tourism expenditure by non-Scottish households is classified as an export. In any time period the standard CES function allocates household consumption expenditure across commodities and within commodities between domestically produced goods and imports.

In the conventionally labelled backward-looking models, decisions made concerning consumption and investment are based solely on the current economic conditions. Therefore in the backward-looking variants, in each time period real consumption is a linear function of present real disposable income. However, in the forward-looking case, the household's 
consumption decisions optimise its lifetime utility subject to a lifetime wealth constraint. This optimisation is carried out through the representative consumer determining the optimal time path of consumption across all the time periods of the simulation.

Turning to investment, in the first period the capital stock is fixed both in total and in its sectoral composition. Thereafter, each sector's capital stock is updated between periods through investment. That is to say, increases and reductions in the capital stock are made through gross investment being greater or less than capital depreciation, with this investment decision always subject to adjustment costs. In the backward-looking variants, investment in each period is a partial adjustment of the existing capital stock to what would be its optimal level, given the sector's current price, output and costs.

In the forward-looking model, the investment adjustment path is the outcome of firms in each sector solving an inter-temporal optimisation problem, where all future economic conditions are known.

For all the variants of the CGE model, a single Scottish labour market with perfect sectoral mobility is imposed. The labour force is taken to be fixed, with employment changing through variations in the unemployment rate. The real wage is determined via an econometrically parameterised bargaining function (Layard et al, 1991). Under this specification, the regional real consumption wage is directly linked to workers' bargaining power, which is inversely related to the unemployment rate.

\section{Simulation strategy}

We undertake simulations using first the standard IO approach and then a number of different variants of the AMOS CGE model. In each simulation the same exogenous tourism expenditure injection is used (described in Section 2) and each model is parameterised on the same base year data set. Therefore the outcomes from using different models to identify the economy wide impact of this expenditure are directly comparable. 
For the Glasgow 2014 Commonwealth Games there was a seven year pre-announcement period, so that in each simulation the tourism disturbance is introduced as one-off exogenous direct tourism demand shock in period 7 . The model simulations are then continued over a subsequent 43 periods so that the impact of the increased tourism expenditure is measured over 50 periods. In real time, period 1 is 2008 , period 7 is 2014, the year in which the Games took place, and the model is then run forward to 2057. The detailed direct expenditure breakdown is given Table A.1 in Appendix A. The sectors that are the main direct recipients are Accommodation, Food and beverage services, and Wholesale and retail. In total these three sectors receive $74 \%$ of the direct expenditure.

Our simulation strategy is outlined in Figure 2. This is simply an aide memoire, a reference to help readers to identify the assumptions behind the simulation labels. The range of simulation results is designed to show the impact of varying the supply-side constraints and the extent of flexibility that economic agents are allowed in the model. Our preferred simulation, with reservations, is the CGE model with both forward-looking behaviour and pre-announcement. The alternative results show the differences in simulation outcomes if alternative model specifications which have been used in the past to quantify the impact of mega events were adopted.

After the 10 simulation, which acts as a benchmark, the CGE simulations are sequenced primarily to identify the effect of increasing the scope for production and consumption adjustment and the degree of rationality attributed in the model to firms and consumers. We are particularly interested in the implications of forward-looking behaviour on the size and temporal distribution of the aggregate economic impact of the temporary tourism expenditure. Studying this variation is important because of uncertainty concerning the appropriate degree to which agents - here firms and consumers - should be assumed to adopt forward looking behaviours. 
Figure 2: Alternative model specification and simulation names

No supply constraints

Labour and capital fixed

CGE -SR

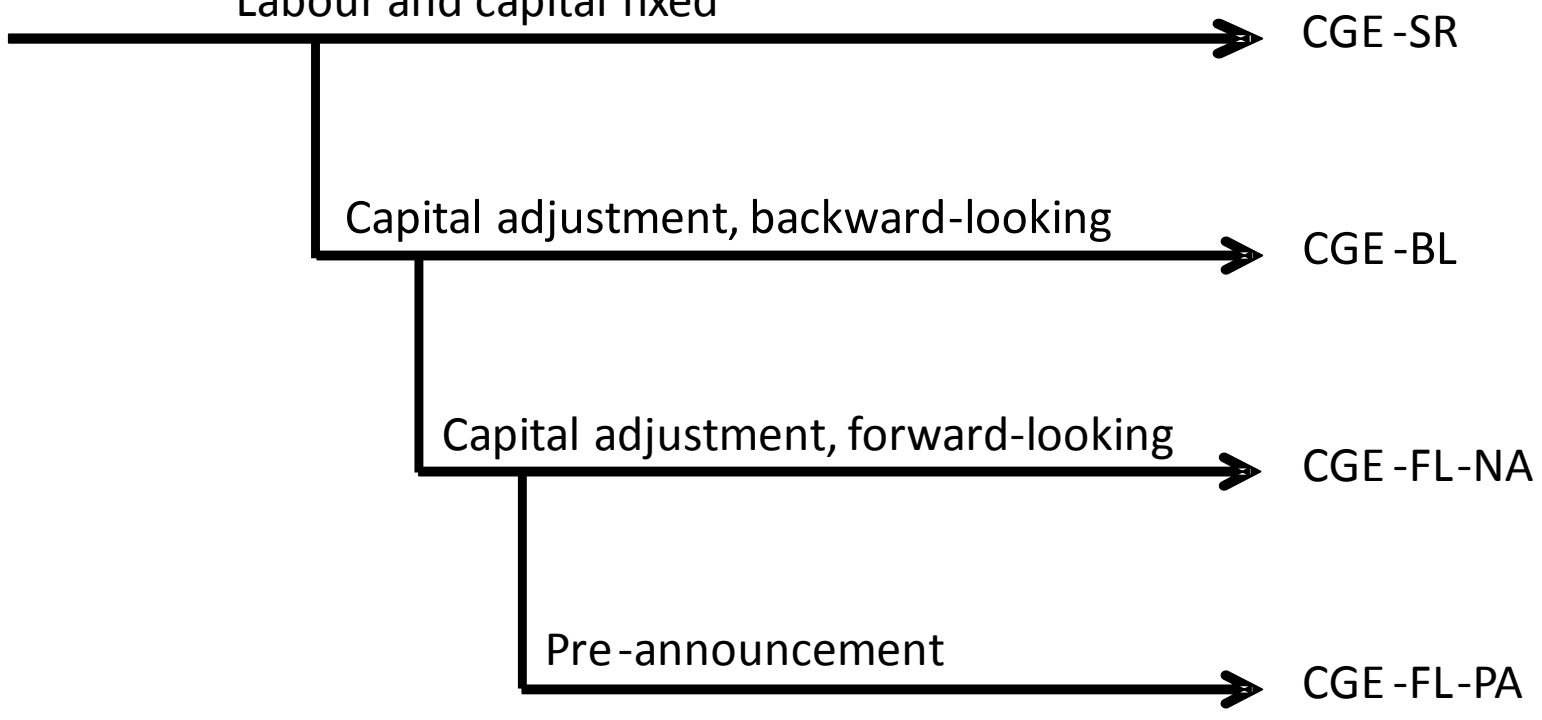

Source: The authors

We begin by implementing a Type I IO multiplier model which we refer to simply as IO. The Type I multiplier reflects present Scottish Government practice in quantifying the impact of final demand stimuli. The method generates a timeless impact (Miller and Blair, 2009, p. 653). In the 10 interpretation we therefore assume the impact is concentrated solely in 2014 , the year of the Games: there is no requirement to adjust capacity before the demand shock and the economy returns to its original equilibrium in the period immediately after the Games8. If it were thought that in reality it would take time for the demand impacts to cascade through the system then the effects on economic activity could be distributed across periods subsequent to 2014. However, the undiscounted cumulative total would remain unchanged.

We then run four CGE simulations. In all cases the labour force is fixed over the whole 50 periods, with the real wage determined by the wage curve. Therefore any increase in employment reduces the unemployment rate and increases the real wage. Similarly, in the 
CGE models, the productive capacity in any industry, relative to demand, will affect the product price and profitability. These price changes trigger supply-side substitution and competitiveness effects. The four simulations differ in respect of the nature and degree of adjustment allowed to household consumption and the capital stock. The capital stock adjustment occurs in all sectors through changes in net investment.

The first CGE simulation, which labelled as CGE-SR, is a standard short-run specification where there is no capital adjustment either in anticipation of, or in response to, the temporary demand shock. There is also no shifting of consumption across periods. This implies that the simulation results deviate from the initial equilibrium only in 2014 . As soon as the temporary tourism expenditure is withdrawn, the economy immediately returns to the initial equilibrium.

In the second CGE simulation, labelled CGE-BL, the economic agents make backward-looking adjustments. This implies that they fail to anticipate the tourism expenditure shock even though it has been pre-announced and then subsequently react in a recursive way. This implies that there will be no change in the equilibrium in the first 6 periods (between 2007 and 2013), but in 2014 and subsequent periods, there will be economic impacts. This is because the 2014 tourism demand shock not only expands output and profitability but also leads to firms increasing investment. This increased productive capacity produces subsequent supply-side impacts. Allan et al. (2008) and Gilmartin and Allan (2014) investigate similar legacy effects with backward-looking investment behaviour in the analysis of the impact of new energy developments.

The third and fourth CGE simulations both adopt forward-looking behaviours by firms and households. The two forward-looking simulations differ in that in the first, labelled CGE-FLNA, there is no pre-announcement. This means that again for the first 6 periods the simulation results do not deviate from the initial equilibrium. However, once the tourism stimulus has occurred, economic agents know that it is temporary but react in a fully forward-looking manner from that point on. In the second forward-looking CGE simulation the fact that the stimulus will occur in period 7 (2014) is announced in period 1 (2008). This simulation is labelled CGE-FL-PA. In this case we expect some change in activity in the first 6 periods as 
firms invest and consumers spend in advance of the temporary demand stimulus. As stated earlier this is our preferred simulation with some reservations which are discussed in the conclusions.

All the model results are presented as deviations from the initial equilibrium values. For each of the simulations four representations of the impact are shown. In Table 2 we report the impact on a range of key economic variables in period 7 (2014), the year in which the Games, and therefore also the temporary tourism stimulus, takes place. In Table 3 we give the 2014 change in output broken down by sector. Table 4 reports the undiscounted cumulative change in GDP and employment over the full 50 year period (2008 to 2057). Finally Figures 3, 4 and 5 show the period by period adjustment to GDP, employment and investment respectively for the backward and forward-looking CGE simulations.

\section{Simulation results from alternate $I O$ and CGE model specifications}

In this section we report the simulation results for the five model specifications outlined in Section 5. Recall that the IO model represents a system with no supply constraints whilst the CGE models embody varying degrees of supply restrictions and behavioural assumptions. We report and explain these results in some detail because the strength of a CGE model lies not in its predictive role as a black box, but rather as a numerical tool for enhanced understanding.

\subsection{IO: Type I Input Output}

The impact on aggregate economic activity in 2014, as measured using the Type I Input Output (IO) model, is shown in the first column of Table 2. GDP increases by $0.066 \%$ and employment by $0.098 \%$. This result reflects output, GDP and employment multiplier values of $1.38,1.36$ and 1.22. Table 3 shows that in the 10 case all sectors benefit from the increase in tourism demand, with the proportionate impact greatest in the Accommodation, Food and beverage services, and Recreational services sectors. In these sectors, output increases by $1.606 \%$, $0.520 \%$ and $0.232 \%$ respectively. 
Recall that in the 10 simulation, the full impact is assumed to occur in the period of the disturbance (2014). Therefore the results shown in Table 2 for the GDP and employment impacts are the same as those for the cumulative impacts reported in Table 4 where they are expressed as absolute values. Using the Type I IO model, the $f 100$ million tourism expenditure is estimated to produce a direct and indirect increase in GDP and employment of $f 68$ million and 2,440 respectively.

In reporting the 10 results, the majority of the entries in the first column of Table 2 are blank, which reflects the assumption of passive supply. The IO model imposes fixed prices and wages rates and here treats all the other elements of final demand, aside from tourism expenditure, as unchanged. Also, given that we use a Type I multiplier, household consumption is also taken to be constant. The only variable where there is some ambiguity is in the change in the unemployment rate. Although with an increase in employment we would expect a reduction in unemployment, 10 is simply silent on the assumed dynamics of the labour market.

Table 2: The 2014 percentage change in key economic variables from their base year values for all simulation models*

\begin{tabular}{lccccc}
\hline & IO & CGE-SR & CGE-BL & CGE-FL-NA & CGE-FL-PA \\
\hline GDP & 0.066 & 0.010 & 0.012 & 0.008 & 0.014 \\
Consumer Price Index & - & 0.088 & 0.095 & 0.057 & 0.045 \\
Unemployment Rate & - & -0.265 & -0.303 & -0.200 & -0.263 \\
Total Employment & 0.098 & 0.017 & 0.019 & 0.013 & 0.017 \\
Nominal Gross Wage & - & 0.115 & 0.125 & 0.077 & 0.071 \\
Real Gross Wage & - & 0.027 & 0.030 & 0.020 & 0.026 \\
Replacement cost of capital & - & 0.037 & 0.057 & 0.011 & 0.011 \\
Households Consumption & - & 0.021 & 0.025 & -0.047 & -0.037 \\
Investment & - & - & 0.080 & -0.037 & -0.054 \\
Capital Stock & - & - & - & - & 0.009 \\
Export RUK & - & -0.059 & -0.067 & -0.033 & -0.033 \\
Export ROW & - & -0.074 & -0.082 & -0.046 & -0.043 \\
Multipliers & & & & & \\
$\quad$ Output & 1.383 & 0.435 & 0.508 & 0.275 & 0.360 \\
$\quad$ GDP & 1.357 & 0.213 & 0.244 & 0.160 & 0.204 \\
$\quad$ Employment & 1.224 & 0.211 & 0.242 & 0.159 & 0.211 \\
\hline
\end{tabular}

* The various model set-ups are explained in Figure 2. 
Of the standard fixed-price demand-driven models, the Type I multiplier approach adopted here gives the most conservative estimates in that it takes no account of any increase in consumption that would accompany the rise in household income associated with expansion in employment (Miller and Blair, 2009). Simulations using the IO Type II or SAM multipliers would give much higher impacts (Emonts-Holley et al., 2015). ${ }^{8}$

\subsection{CGE-SR: Conventional Short-Run CGE}

In the conventional short-run CGE simulation, CGE-SR there is no adjustment to the capital stock either before or after the tourism expenditure disturbance. This is the type of simulation used by Zhou et al (1997) and Bohlmann and Van Heerden (2005; 2008). The results are reported in the second column of Tables 2, 3 and 4 . The figures reveal that the assumption of restricted supplies of capital and labour severely reduces the predicted impact of the tourism shock. In this simulation in 2014 GDP and employment increase by $0.010 \%$ and $0.017 \%$ respectively, which is less than $20 \%$ of the predicted impact using the 10 model.

The reasons are very straightforward. The stimulus to employment generates an increase in the real wage of $0.027 \%$ which is achieved through a rise in the nominal wage of $0.115 \%$ and an increase in the consumer price index of $0.088 \%$. The higher prices reduce competitiveness so that exports to the rest of the UK (RUK) and the rest of the world (ROW) fall. Whilst the increase in tourism expenditure increases household consumption, it crowds out exports, thereby limiting the positive impact on overall economic activity. The output, GDP and employment multipliers again show the total period-10 impact on these variables, as measured against the direct values embedded in the tourism shock. Note that all these

\footnotetext{
${ }^{8}$ The Type II IO multiplier endogenises not only the demand for intermediate inputs but also household consumption (Miller and Blair, 2009). Its value can never be less than the corresponding Type I multiplier. In this case, the Type II output, GDP and employment multipliers are $2.71,2.04$ and 1.65 respectively.
} 
multipliers are considerably less than one. This implies that the net impact on the Scottish economy is less than the direct impact.

The sectoral breakdown of output changes under the CGE-SR simulation are given in column 2 of Table 3. Note that the impact on those sectors strongly directly affected by tourism expenditure, such as Accommodation and Food and beverage services, is lower than in the 10 result, reflecting the short-run capacity restrictions. However, much more importantly, there are also output reductions in the majority of other sectors, caused by crowding out generated by higher nominal wages and prices. As was stated earlier, in this simulation all the impacts occur in 2014. Therefore for CGE-SR the cumulative effect reported in column 2 of Table 4 is again simply the absolute values that correspond to the proportionate changes shown in Table 2. 
Table 3: The 2014 percentage changes in sectoral outputs from their base year values for all simulation models*

\begin{tabular}{|l|c|c|c|c|c|}
\hline & & \multicolumn{4}{|c|}{ CGE } \\
\cline { 2 - 5 } Agriculture, forestry and fishing & IO & SR & BL & FL-NA & FL-PA \\
\cline { 2 - 6 } Mining & 0.079 & 0.005 & 0.004 & 0.003 & 0.013 \\
Food, drink and tobacco & 0.011 & -0.018 & -0.020 & -0.011 & -0.013 \\
Textile, leather, wood and paper & 0.096 & 0.007 & 0.003 & 0.011 & 0.024 \\
Chemicals & 0.088 & 0.003 & 0.000 & 0.011 & 0.018 \\
Rubber, plastic, cement and iron & 0.062 & -0.004 & -0.008 & 0.004 & 0.010 \\
Computer, electrical and transport & 0.032 & -0.051 & -0.049 & -0.043 & -0.040 \\
equipment & & & & & \\
Electricity, gas and water & 0.016 & -0.055 & -0.058 & -0.047 & -0.046 \\
Construction & 0.018 & -0.018 & -0.021 & -0.025 & -0.023 \\
Wholesale and retail & 0.012 & -0.024 & 0.017 & -0.050 & -0.058 \\
Land transport & 0.101 & 0.049 & 0.050 & 0.026 & 0.037 \\
Water transport & 0.123 & 0.052 & 0.050 & 0.043 & 0.055 \\
Air Transport & 0.063 & -0.005 & -0.016 & -0.002 & 0.006 \\
Post and support transport services & 0.033 & -0.007 & -0.009 & -0.017 & -0.013 \\
Accommodation & 0.073 & -0.013 & -0.017 & -0.006 & 0.002 \\
Food \& beverage services & 1.606 & 1.410 & 1.411 & 1.379 & 1.452 \\
Telecommunication & 0.520 & 0.433 & 0.434 & 0.389 & 0.424 \\
Computer and information services & 0.057 & 0.005 & 0.006 & -0.006 & 0.001 \\
Financial services & 0.026 & -0.044 & -0.038 & -0.035 & -0.036 \\
Real estate & 0.015 & -0.026 & -0.029 & -0.020 & -0.022 \\
Professional services & 0.031 & 0.018 & 0.022 & -0.006 & -0.003 \\
Research and development & 0.041 & -0.034 & -0.033 & -0.023 & -0.021 \\
Public administration & 0.014 & -0.087 & -0.091 & -0.059 & -0.055 \\
Recreational services & 0.008 & 0.011 & 0.013 & -0.001 & 0.000 \\
Other services & 0.232 & 0.186 & 0.187 & 0.157 & 0.173 \\
& 0.055 & 0.025 & 0.025 & -0.004 & 0.005 \\
\hline
\end{tabular}

* The sectors are defined in Table A1 in Appendix A and the various model set-ups are explained in Figure 2. 
Table 4: Cumulative undiscounted absolute changes in key economic variables over the 50periods for each simulation model ${ }^{*}$

\begin{tabular}{|l|c|c|c|c|c|}
\hline & \multirow{2}{*}{10} & \multicolumn{4}{|c|}{ CGE } \\
\cline { 3 - 6 } & IO & SR & BL & FL-NA & FL-PA \\
\hline Cumulative GDP change (fm) & 67.6 & 10.6 & 37.5 & -4.7 & 19.6 \\
\hline $\begin{array}{l}\text { Cumulative employment } \\
\text { (year) change }\end{array}$ & 2440 & 421 & 895 & 167 & 587 \\
\hline
\end{tabular}

* The various model set-ups are explained in Figure 2.

\subsection{CGE-BL: Dynamic backward-looking CGE}

Results from the backward-looking CGE simulation, CGE-BL, are shown in column 3 of Tables 2, 3 and 4. The impact in 2014 is similar to that for the conventional short-run simulation, CGE-SR, though the GDP and employment increases of $0.012 \%$ and $0.019 \%$ are slightly higher. This is because in the backward-looking case, firms' investment decisions are affected by the changes in economic activity occurring in 2014. Specifically, firms attempt to adjust their capital stock, based upon present prices and output. In 2014 the price of capital is falling relative to labour and output generally is rising. There is therefore an increase in investment of $0.080 \%$, which is an additional stimulus to demand in that period which is not present in the standard short-run simulation, CGE-SR. This is reflected in the sectoral results shown in Table 3. Whereas in the short-run simulation CGE-SR the output in construction falls in 2014 by $0.024 \%$, in the backward-looking simulation, CGE-BL, it increases by $0.017 \%$.

The higher investment in 2014 generates an addition to the capital stock that comes into service in 2015 and delivers a supply-side stimulus to the economy. This positive stimulus remains, but at a falling level as the capital stock gradually returns to its original value. The temporal evolution of the GDP figures is shown in Figure 3. Whilst GDP change peaks in the year of the Games, there is a continuing positive impact driven by the increased capacity laid down in that year and the employment results show a similar pattern over time. However, the increased investment in period 2014 leads to subsequent excess capacity. This reduces 
the capital rental rate, relative to the wage, so that the employment figures shown in Figure 4 are less strongly maintained than GDP in the post-shock period.

Figure 3: Period-by-period \% changes from base year values in Scottish GDP accompanying

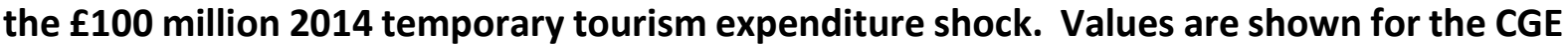
backward- (CGE-BL) and forward-looking models without (CGE-FL-NA) and with (CGE-FL-PA) pre-announcement.

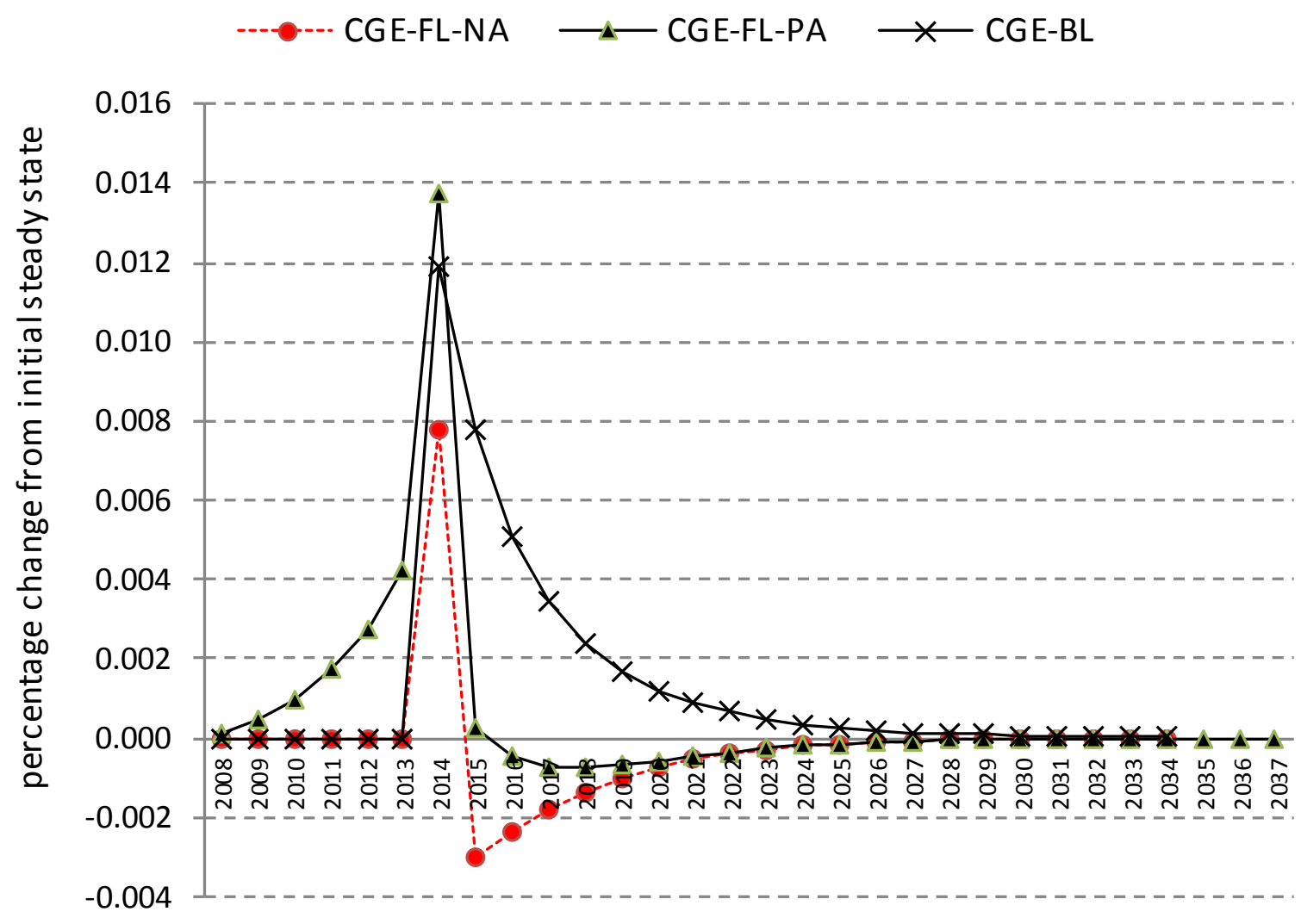


Figure 4: Period-by-period \% changes from base year values in Scottish employment accompanying a $\mathbf{1 1 0 0}$ million 2014 tourism expenditure shock for the CGE backward- (CGEBL) and forward-looking models without (CGE-FL-NA) and with (CGE-FL-PA) preannouncement.

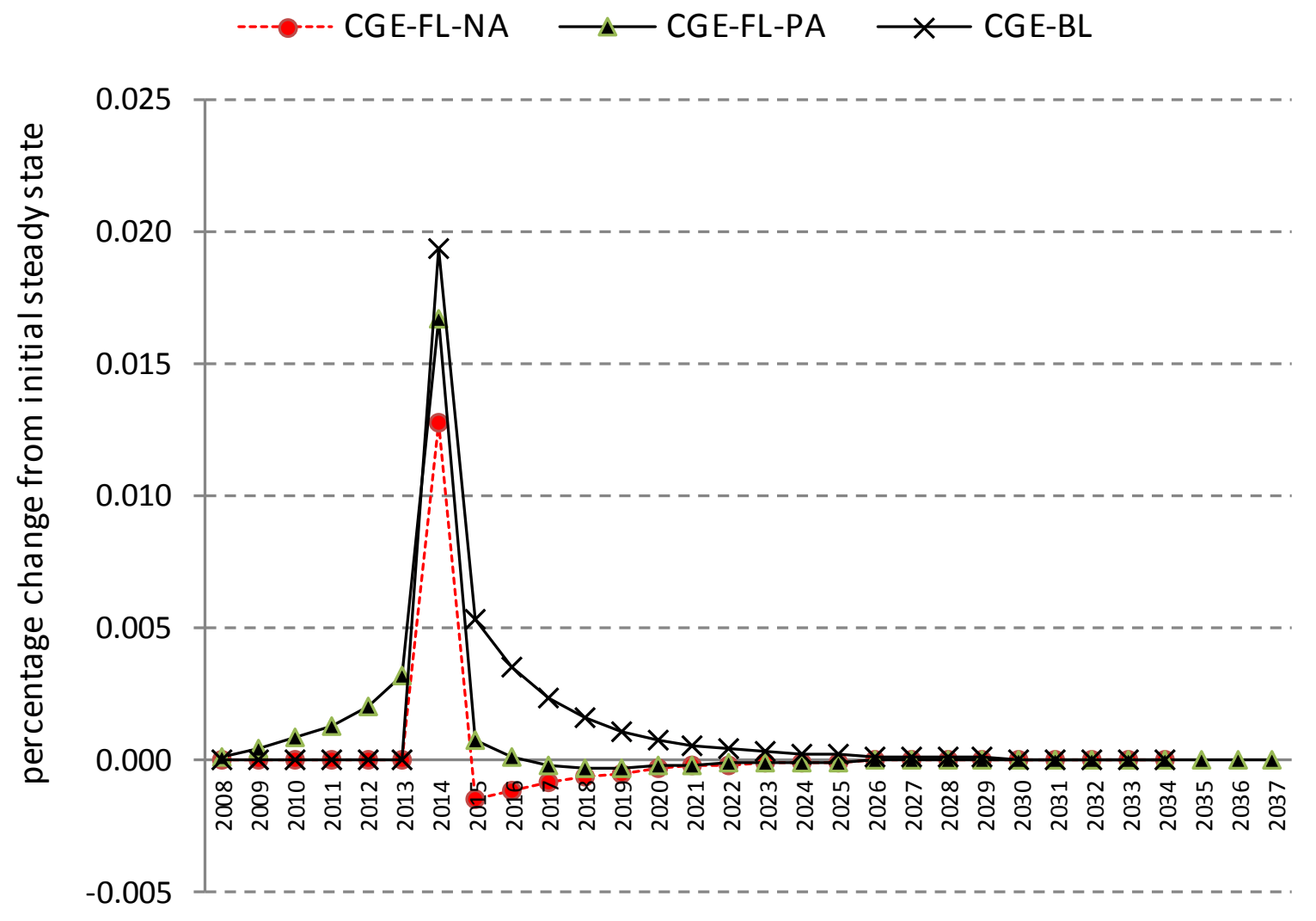

The investment figures are presented in Figure 5 and reveal the positive spike in 2014 and subsequent disinvestment as the capital stock gradually readjusts. However, the negative demand-side effects of the disinvestment are clearly not large enough to offset the supplyside stimulus from the continuing higher level of capacity. This is reflected in the cumulative GDP and employment results reported in column 3 of Table 3. In this backward-looking simulation the cumulative GDP impacts are $£ 37.5$ million. Whilst this is around $55 \%$ of the 10 value, it is over three and a half times as large as the value for the standard short-run simulation, CGE-SR, where these legacy effects do not occur. In the CGE-BL simulation over $67 \%$ of the undiscounted GDP impact occurs subsequent to 2014 . For the employment impact 
the result is less sanguine; cumulatively 895 employee years are generated, less than $40 \%$ of the 2440 employee years reported in the 10 simulation.

Figure 5: Period-by-period \% changes from base year values in Scottish aggregate investment accompanying a $£ 100$ million 2014 tourism expenditure shock for the CGE backward- (CGE-BL) and forward-looking models without (CGE-FL-NA) and with (CGE-FLPA) pre-announcement.

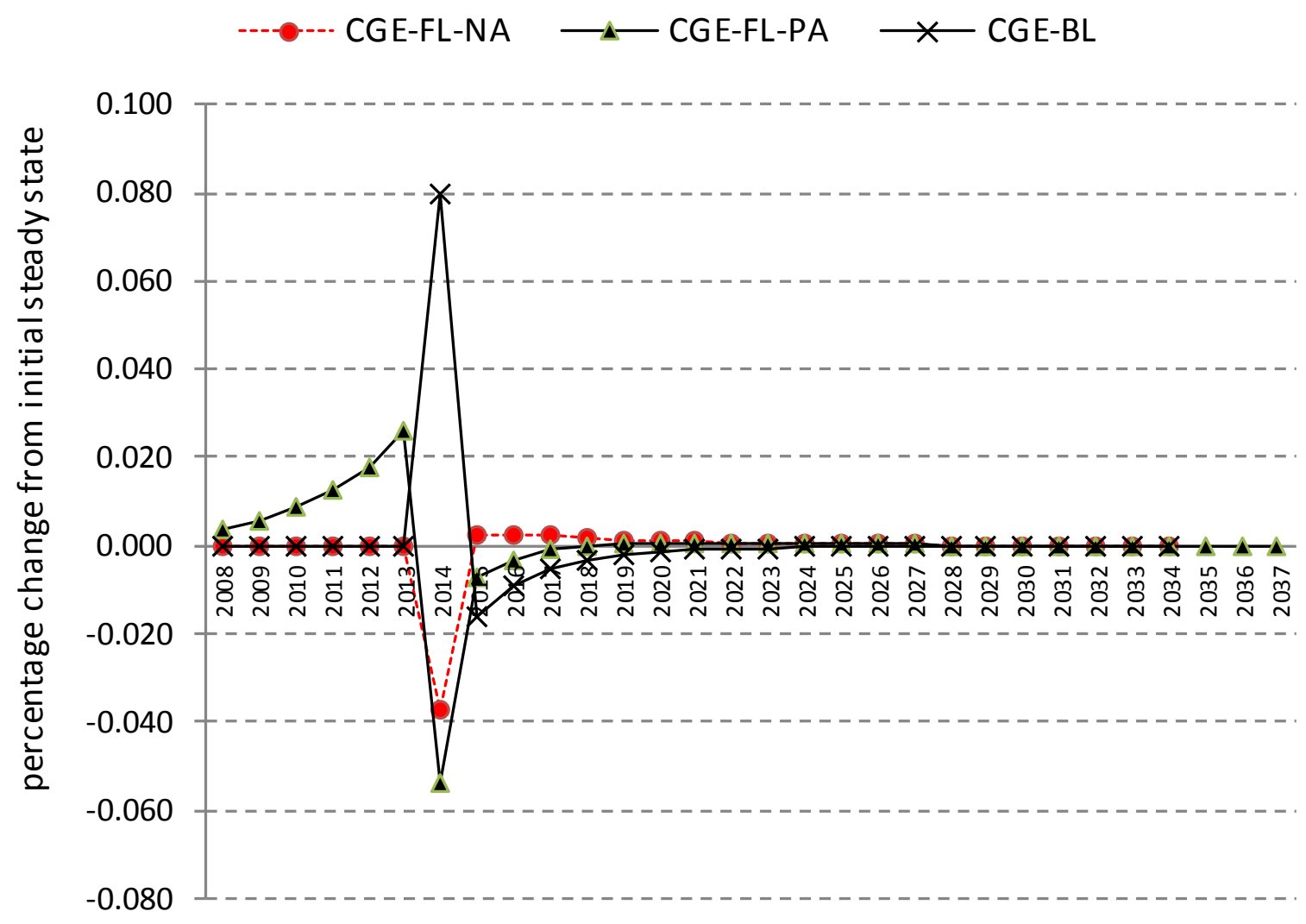

\subsection{CGE-FL-NA: Forward-looking CGE with no pre-announcement}

Column 4 of Table 2 shows the period-7 (2014) simulation results for the forward-looking CGE model with no pre-announcement, CGE-FL-NA. Again, the 2014 results are very similar to those for the short-run and backward-looking models, except in this case slightly smaller; GDP and employment increase by $0.008 \%$ and $0.013 \%$ respectively. The reason is that in this case 
forward-looking firms and households reduce their investment and consumption expenditures in the period of the shock because of the relatively high wage and intermediate input costs generated by the exogenous increase in tourism demand. Whilst firms and households were not able to plan for the increase in tourism expenditure, they are aware it is a temporary disturbance and therefore will adjust subsequent expenditure. This implies that in the period of the Games there is a degree of crowding out in household consumption, investment and exports. In terms of sectoral effects, as reported in column 4 of Table 3, the most prominent result is the 0.050 reduction in Construction and the much lower increase in Wholesale and retail when compared to the previous models.

The impact of the lower investment in 2014 on subsequent GDP and employment is shown in Figures 3 and 4. Note that in this case there is a sizable reduction in GDP in the periods subsequent to the tourism shock as a result of the lower capital stock. This is also reflected in the employment figures, although again the impact is less extreme. Figure 5 shows the path of investment. After the $0.037 \%$ reduction in investment in 2014 there are subsequent small increases. However, their effect on aggregate demand is not large enough to offset the negative supply-side impact of the lower capital stock. The cumulative undiscounted results for the simulation CGE-FL-NA are shown in column 4 of Table 4 . They indicate a negative cumulative GDP effect of $£ 4.7$ million and a small 167 employment increase.

\subsection{CGE-FL-PA: Forward-looking CGE with 7 -period pre-announcement}

The results for the last simulation are given in column 5 of Table 2. This is for the model where agents are forward looking and the tourism stimulus is pre-announced by 7 periods (CGE-FLPA). This specification appears to be of the type used in Blake (2005), which considers the impacts of the 2012 London Olympics. This degree of pre-announcement corresponds to the actual situation for the 2014 Commonwealth Games. Of all the CGE simulations, this is the one that gives the highest impact in the actual period of the Games. In 2014 GDP and employment increase by $0.014 \%$ and $0.017 \%$. This is to be expected given that firms have brought forward investment expenditure to have greater capacity so as to be able to take advantage of the temporary tourism expenditure injection. Capital stock is $0.009 \%$ higher and as a result the consumer price index only increases by $0.045 \%$ and there is relatively low 
crowding out of RUK and ROW exports. However, as we would expect, the period 2014 investment and household consumption expenditures are $0.054 \%$ and $0.037 \%$ lower respectively than in the base period.

The impact on sectoral outputs is shown in column 5 of Table 3. Compared to the other CGE simulations, output increases strongly in those sectors which experience the demand shock e.g. Accommodation and Food and beverage services. These are sectors in which the capital stock has increased proportionately the most through prior investment. However, note also the big fall in construction of $0.058 \%$, the largest for all the simulations. It is clear that even though there is pre-announcement, the output in 2014 still falls in 11 of the 25 sectors.

The time paths for GDP and employment are given in Figures 3 and 4. The striking characteristic of the results with the CGE-FL-PA variant of the model is the build-up of economic activity in advance of 2014. This increase in activity is driven by investment and household consumption decisions' being brought forward, anticipating the direct tourism disturbance. In 2015 there is still a continuing small stimulus. However, after 2015 both GDP and employment are lower than their base year values: there is a negative economic "hangover", rather than positive legacy effects. The time sequence of investment expenditure is shown in Figure 5. Note the build-up of investment prior to 2014, the large negative value for 2014 itself and the subsequent disinvestment until the initial capital stock level is reached.

The cumulative values are given in column 5 of Table 3 . For this simulation the cumulative undiscounted increase in GDP is $f 20$ million and employment is 587 . These figures are around a third and a quarter the 10 values. It is clear that the opportunity for forward-looking agents to adjust capacity as a result of pre-announcement relaxes some of the supply constraints operating in the period of the shock. It also increases impact by bringing forward investment expenditure although the accompanying result is negative legacy effects. Nevertheless, forward-looking behaviour in itself does not necessarily enhance the effect of temporary demand shocks on the regional economy. The lowest cumulative stimulus is given by the forward-looking model with no pre-announcement, where GDP effects are actually negative. Also the largest cumulative impact from the CGE models comes with backward-looking 
investment behaviour, although this is clearly sub-optimal ex post, from the firms' perspective.

\section{Varying the degree of pre-announcement}

In Section 6 we consider only one level of pre-announcement. This is where the event is announced 7 years in advance. We report that for the forward-looking model, the 7-period pre-announcement significantly increases the local economic impact, as measured against no preannouncement. However, it is of interest to test the sensitivity of the results to varying the degree of pre-announcement. To this end, we run the forward-looking model 20 times. In each simulation we pre-announce in period zero the period in which the tourism consumption injection will take place. The demand shock is then entered for each time period between zero and 19. Therefore with no preannouncement, the cumulative result is shown under period zero, with one period pre-announcement under period 1, etc. We only report the GDP impacts here but similar analysis could be carried out for other relevant variables, such as employment or household income.

For the forward-looking model, the undiscounted cumulative GDP impact increases continuously with the degree of pre-announcement, but at a decreasing rate. However, in considering the optimal pre-announcement period it is more useful to calculate the present value of the GDP changes that accompany the tourism shock. The present value of a tourism shock announced in period zero that will take place in period T, $P V_{G D P}^{T}$, is given as:

$$
P V_{G D P}^{T}=\sum_{t=0}^{49} \frac{G D P_{t}^{T}}{(1+r)^{t}}
$$

where $G D P_{t}^{T}$ is the difference between GDP in time period t and the base period value for a simulation with a pre-announcement of T periods, and $r$ is the discount rate. 


\section{1: Simulation results}

The GDP present values of the tourism shock with alternate levels of pre-announcement and discount rates are shown in Figure 6. The central calculations use the $3.5 \%$ real discount rate recommended in the HM Treasury Green Book (HM Treasury, 2003). It is clear that the degree of pre-announcement has a big influence on the present value of the change in GDP. In the case under consideration here, with no pre-announcement this value is negative, whilst with the optimal 9-year pre-announcement it stands at just below $f 18$ million. Increasing the level of preannouncement from 3 years to 9 years more than doubles the discounted benefit to GDP. We also show in Figure 6 the sensitivity of the results to variations in the discount rate. Decreasing the discount rate to $2 \%$ increases the optimal degree of pre-announcement to 10 periods whilst increasing the discount rate to $5 \%$ reduces the optimal degree of preannouncement to 7 periods.

Figure 6: The change in the present value of GDP with various degrees of pre-announcement and discount rates, fmillions (2009 prices)

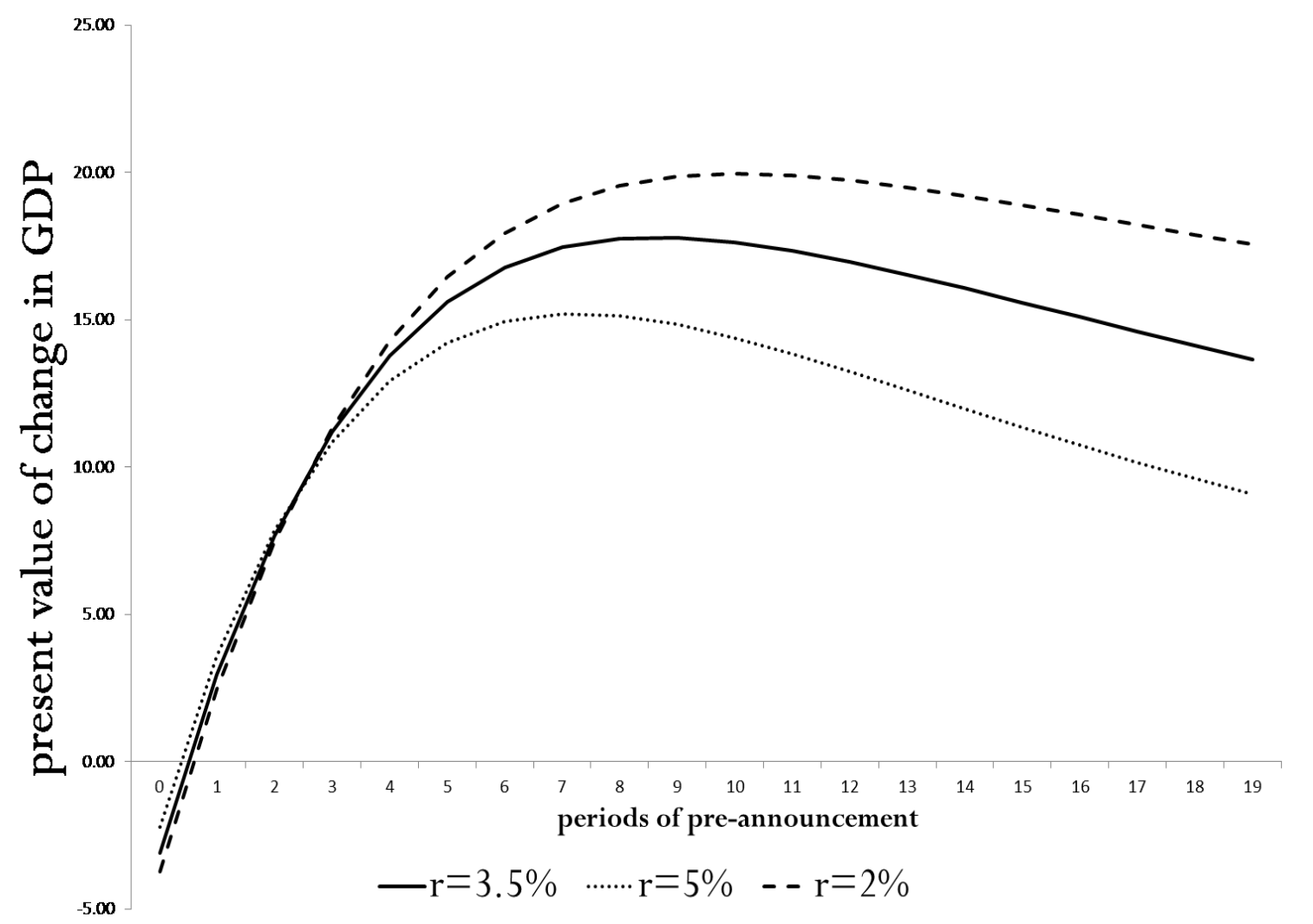




\subsection{Practical Implications}

It is important to be clear how this information should be interpreted. Imagine that the only benefit for the country hosting the Commonwealth Games were the economic stimulus generated by tourism spending. If the Commonwealth Games organising committee wished solely to maximise the GDP benefit to a host country similar to Scotland, it would decide and announce the venue nine years before the event. If the lead time were greater, the actual undiscounted GDP benefit would be higher but would be delivered at a later date which would have a smaller present value.

However, with these results, once the decision has been taken concerning the venue, there is no advantage to withholding that information. For example, imagine that a decision has been taken that 15 years hence an event comparable to the Commonwealth Games will take place in Scotland. It is not optimal to hold back that information for six years, on the basis that the present value of the increase in GDP is maximised with a nine year pre-announcement. What needs to be compared in that situation is the present value of the 15 year preannouncement against the present value of a nine year pre-announcement made in six years' time. If the pre-announcement is delayed for six years, this reduces the present value of the f18 million optimal figure by $18.65 \% .{ }^{9}$ However, the longer preannouncement only reduces the present value by $12.43 \%$, as against the optimal nine year value.

The arguments presented here are strongly intuitive. The more advanced warning the economy is given of a temporary demand shock, the easier it is for households and firms to smooth consumption expenditure and augment the capital stock to exploit the expenditure injection. These adjustments reduce crowding out in the period of the shock itself and increase the real GDP impacts. However, Blake (2009), using a very similar CGE approach, comes to the opposite conclusion. He states: "The implications for policy makers are that ... the benefits of tourism are ... lower when a tourism boom is anticipated and this is of particular concern when considering the benefits of future events ... such as major sporting and other special events" (Blake, 2009, p. 627). It is difficult to understand how this result was

\footnotetext{
${ }^{9}$ This is calculated as $\left(1-(1 / 1.035)^{6}\right) \times 100$.
} 
achieved. It is justified with the statement that "Tourism demand shocks rely on increases in prices to provide welfare benefits" (Blake, 2009, p. 626). The implication appears to be that price smoothing achieved through appropriate forward-looking behaviour facilitated by preannouncement is welfare reducing. However, this seems inconsistent with Blake's own analysis that the maximum increase in GDP is achieved, as in our model, under the InputOutput simulations where there are no changes in prices.

The model in Blake (2009) does not have the exact same structure as our own but it shares many common features and it is unclear why the two models operate in such a different manner. The Blake model is a national (UK) model, which implies a requirement to meet certain macroeconomic constraints which do not typically operate in a regional (Scottish) model. Further, Blake (2009) gives no explicit account of how the labour market is treated and no employment figures are reported for his simulations. This is itself curious, given that the employment effect of the tourism stimulus is often a key policy interest. Blake (2009, p. 617) suggests that it is appropriate for CGE models to have natural rate long-run characteristics but the particular features of the short-run labour market are not given. Finally, the key parameter values might well be very different for some key sectors. It is a puzzle that the two studies come up with such radically different conclusions. More detailed comments on Blake (2009) are given in Allan et al (2014). However, we are confident over our results as they apply to an open regional economy.

\section{Conclusions}

This paper models the impact on the Scottish economy of the $f 100$ million expenditure from non-Scottish tourists associated with the Glasgow 2014 Commonwealth Games in Scotland. We undertake a number of simulations with different assumptions concerning consumption and investment behaviour. In using the same tourism expenditure shock and the same structural data to parameterise the model, we can test the sensitivity of the results to model specification. Our preferred estimates are those using the forward-looking CGE model with preannouncement. This gives the results that the cumulative (undiscounted) impact on GDP and employment was $£ 19.6$ million and 587 person years of employment respectively. These lie between the estimates made using the more standard IO or short-run CGE approaches 
(albeit our preferred estimates are much closer to the short-run CGE results). The simulations also show that the scale and timing of these effects depend upon the degree to which economic agents are forward-looking and the extent of pre-announcement of the event.

It is important to raise one reservation concerning our preferred figures and this would repay further investigation. In this paper we have assumed that agents are either completely backward-looking or that they are forward-looking with perfect foresight. It is clear that actual agents will be somewhere in between. It seems wholly unrealistic to model agents' behaviour in this case as completely backward-looking. This implies that firms in tourism industries are not aware that the increase in demand is only temporary, though firms in linked industries might be less well informed. However, the forward-looking behaviour we model involves perfect foresight. This means that the agents not only know the size and timing of the shock but can accurately model the operation of the economy and the reaction of other agents to the shock. This is asking too much. The first indicative projections of the additional tourism expenditure from outwith Scotland expected to be generated by the Commonwealth Games were only available less than 4 months before the Games started (Scottish Government, 2014). Therefore there must be some uncertainty about any prior estimate of the direct tourism expenditures and also the way in which the Scottish economy will react.

A key element of the analysis is the investigation of the impact of varying the degree of preannouncement and the serious questioning of the only other, to our knowledge, work on this issue. Where forward-looking CGE models are used, the size and timing of local investment and consumption expenditure can be adjusted in an attempt to maximise the benefits, and minimise any costs, from the demand shock. Where there was no pre-announcement, we found the cumulative impact on Scottish GDP was negative. The positive effect during the period of the Games crowds out investment generate subsequent negative legacy effects. However, the pre-announcement of the tourism stimulus has a positive impact on the size of the subsequent economic impacts. Where a $3.5 \%$ discount rate is used a nine-period preannouncement maximises the present value of the subsequent changes in Scottish GDP. This was slightly longer than the actual seven year preannouncement. 
However, this figure is dependent on GDP being the key variable, the discount rate being HM Treasury's 3.5\% and also that there are no other considerations regarding preannouncement. In this respect, it is often the case that mega events are accompanied by prior expenditure on stadia, transport links and other forms of infrastructure (Kuper, 2014; Li and Blake, 2009). The optimal degree of pre-announcement is likely to depend on the cost implications of longer lead times with these projects. This also raises the issue that in this paper the tourism shock is considered in isolation. If there are other construction projects occurring in advance of the mega event, this will increase the cost, and therefore reduce the benefit, of moving investment forward in the tourist sectors.

A final question is: how far is this analysis generalizable? First, do the results from this particular case apply to similar mega events in other regions? Second, can this analysis be used to quantify the economy-wide impact of other temporary tourist expenditure shocks, such as those related to terrorism or a SARS outbreak?

In the case of other mega events, economies are likely to react differently to the tourism shock. The key considerations will be the degree of openness of the economy and its technical flexibility. In this respect, the smaller, and therefore typically the more open, the region, the smaller will be the linked demand effects and the larger any negative price effects. However, whilst the nature of the economy will affect the absolute size of the impacts, it will have less effect on the qualitative relationship between the different modelling results. That is to say, we would expect the standard IO and short-run CGE models to systematically over-estimate and underestimate the actual impacts.

For other types of temporary tourism shock, it is important to recognise key differences from the mega event disturbance. Crucially, in many cases, for example a terrorist attack or epidemic episode, there is no pre-announcement, so that any resulting tourism shock is unanticipated. There is also typically uncertainty as to its duration and severity of the direct tourism expenditure impact. It is also the case that these are almost all negative shocks and they are often linked to other economic shocks which could interact with the change in tourism demand. Formally, we would favour use of the backward or forward-looking CGE model with no pre-announcement. The key issue would be how local firms react to the initial 
reduction and the subsequent uncertain evolution of tourism demand following the event. If the firms are forward looking and confident of future recovery the negative employment impact will be small and there might even by positive GDP effects as local firms use the temporary reduction in demand to invest for the future. However, if backward looking investment behaviour prevails, investment will fall as tourism output falls and the impact of the temporary negative shock will be extended by a loss of competitiveness through underinvestment. These are issues which we wish to pursue in greater depth in future work. 
Appendix A: Sectoral definitions and direct impacts

Table A.1: Sector classification and the sectoral breakdown of the $f 100$ million direct tourism expenditure shock

\begin{tabular}{|l|l|l|r|}
\hline $\begin{array}{l}\text { AMOS } \\
\text { Sector }\end{array}$ & $\begin{array}{l}\text { Scottish IO } \\
\text { Sectors }\end{array}$ & Sector name & $\begin{array}{l}\text { Direct temporary } \\
\text { Tourism expenditure } \\
(\text { fm })\end{array}$ \\
\hline 1 & $1-5$ & Agriculture, forestry and fishing & 0.78 \\
\hline 2 & $6-9$ & Mining & 0.29 \\
\hline 3 & $10-10$ & Food, drink and tobacco & 1.80 \\
\hline 4 & $21-26$ & Textile, leather, wood and paper & 1.78 \\
\hline 5 & $27-32$ & Chemicals & 2.93 \\
\hline 6 & $33-37$ & Rubber, plastic, cement and iron & 0.16 \\
\hline & & Computer, electrical and transport & 0.80 \\
\hline 7 & $38-46$ & equipment & 0.25 \\
\hline 8 & $47-51$ & Electricity, gas and water & 0.24 \\
\hline 9 & $52-54$ & Construction & 16.97 \\
\hline 10 & $55-57$ & Wholesale and retail & 3.02 \\
\hline 11 & $58-59$ & Land transport & 0.33 \\
\hline 12 & 60 & Water transport & 0.17 \\
\hline 13 & 61 & Air Transport & 0.49 \\
\hline 14 & $62-63$ & Post and support transport services & 36.24 \\
\hline 15 & 64 & Accommodation & 20.32 \\
\hline 16 & 65 & Food \& beverage services & 0.90 \\
\hline 17 & $66-69$ & Telecommunication & 0.01 \\
\hline 18 & $70-71$ & Computer and information services & 0.85 \\
\hline 19 & $72-74$ & Financial services & 2.27 \\
\hline 20 & $75-77$ & Real estate & 1.31 \\
\hline 21 & $78-81 ; 83-91$ & professional services & 0.00 \\
\hline 22 & 82 & Research and development & 1.52 \\
\hline 23 & $92-96$ & Public administration & 5.97 \\
\hline 24 & $97-100$ & Recreational services & 0.59 \\
\hline 25 & $101-104$ & Other services & 100.00 \\
\hline $1-25$ & $1-104$ & Total & \\
\hline
\end{tabular}


Appendix B. Key relationships in the AMOS model.

In both the backward- and forward looking specifications of the AMOS model, household consumption expenditure across commodities and within commodities between domestically produced goods and imports, in any time period, $t$, is allocated using the formulation given in equation (1)

$$
H_{i, t}=\beta_{i}^{\rho^{c}} \cdot\left(\frac{P C_{i, t}}{P Q_{i, t}}\right)^{\rho^{c}} \cdot C_{t}
$$

where for sector $i, H_{i}$ is total household consumption, $C$ is the consumption composite good, $P C$ is the aggregate price of consumption, $P Q_{i}$ is the commodity price, $\rho^{c}$ is the elasticity of substitution between commodities and $\beta_{i}$ is the share parameter for commodity. The within period domestic and imported consumption good demands are determined using equations (2) and (3):

$$
\begin{gathered}
H_{i, t}=\gamma_{i} \cdot\left[\phi_{i}^{r} \cdot H R_{i, t}^{\rho_{i}^{A}}+\left(1-\phi_{i}^{r}\right) \cdot H M_{i, t}^{\rho_{i}^{A}}\right]^{1} \\
\frac{H R_{i, t}^{A}}{H M_{i, t}}=\left[\left(\frac{\phi_{i}^{r}}{\left(1-\phi_{i}^{r}\right.}\right) \cdot\left(\frac{P M_{i, t}}{P R_{i, t}}\right)\right]^{\frac{1}{1-\rho_{i}^{A}}}
\end{gathered}
$$

where $H R_{i}, H M_{i}, P R_{i}$ and $P M_{i}$ are the domestic and import consumption quantities and prices respectively, for commodity $i$, while $\gamma_{i}$ and $\phi_{i}^{r}$ are the CES scale and share parameters and $\rho_{I}^{A}$ is the elasticity of substitution between domestic and imported commodities in the household's consumption problem.

In the backward-looking models, the composite consumption in each time period is a linear function of real disposable income whilst in the forward-looking case the household's consumption decisions optimise its lifetime utility subject to a lifetime wealth constraint. This optimisation is carried out through the representative consumer determining the optimal 
time path of consumption in each period of the simulation. The solution of the inter-temporal problem is given in equation (4)

$$
\frac{C_{t}}{C_{t+1}}=\left[\frac{P C_{t} \cdot(1+\lambda)}{P C_{t+1} \cdot(1+r)}\right]^{-\left(\frac{1}{\sigma}\right)}
$$

where $\lambda$ is the rate of consumer time preference, $\sigma$ is the constant elasticity of marginal utility and $r$ is the (exogenous) interest rate. This equation is obtained by applying the required first order conditions to the current-value Hamiltonian (see Barro and Sala-i-Martin, 2004).

The dynamic budget constraint ensures that the discounted present value of consumption does not exceed total household wealth, where there is a distinction between financial and non-financial assets (Lecca et al., 2013). The rate of household saving is exogenous and is not linked directly to investment. This is a standard assumption in regional CGE models where equality between savings and investments need not be maintained.

In the first period, capital stock is fixed both in total and in its sectoral composition, but each sector's capital stock is subsequently updated between periods through investment. In the backward-looking version, this is achieved via a recursive capital stock adjustment procedure which is shown in equation (5). Investment, $l_{i}$, equals depreciation plus some fraction of the gap between actual and desired capital stock for sector $i$ :

$$
I_{i, t}=v \cdot\left[K S_{i, t}^{*}-K S_{i, t}\right]+\delta \cdot K S_{i, t}
$$

where $v$ is the speed of adjustment of capital between the actual and desired level $\left(K S_{i}\right.$ and $K S_{i}^{*}$ respectively) and $\delta$ is the rate of depreciation of sectoral capital stock. The adjustment rule introduced in the myopic model follows that employed in AMOS (McGregor et al., 1996) which is consistent with the neoclassical formulation developed in Eisner and Stroz (1963) and Jorgenson (1963). The speed of adjustment in the investment equation is uniform across all sectors, although in practice some sectors, such as air transport, might be unable to adjust their capital stocks as quickly as others, e.g. cafes (Dwyer et al, 2000). In the forward-looking case, the time path of investment is obtained through the tax-adjusted Tobin's $q$ (Tobin, 
1969). This adjustment path will differ from that in the backward-looking model as the firms' dynamic investment decisions are the outcome of solving an inter-temporal optimisation problem. With assumed quadratic capital adjustment costs, sectors do not instantaneously adjust their capital stock but make a series of investments over time. The core equations for both models are available in Lecca et al. (2013).

Within the model, the real wage is determined through an econometrically parameterised bargaining function (Layard et al, 1991). This wage curve specification takes the following form:

$$
\ln \left[\frac{w_{t}}{c p i_{t}}\right]=B-\psi \ln \left(u_{t}\right)
$$

where $w$ is the nominal wage, $c p i$ is the consumer price index, $u$ is the unemployment rate, $\psi$ is the elasticity of the real wages with respect to the unemployment rate and $B$ is a parameter calibrated to ensure equilibrium in the base year. In the particular labour market configuration used in this paper, the size of the labour force is assumed fixed over the simulation window. 


\section{REFERENCES}

Akkemik, K. A. (2012), "Assessing the importance of international tourism for the Turkish economy: A social accounting matrix analysis", Tourism Management, vol. 33, pp. 790-801.

Allan, G.J., Dunlop, S. and Swales, J.K. (2007), "The economic impact of regular season sporting competitions: The Glasgow Old Firm football spectators as sports tourists", Journal of Sport and Tourism, vol. 12, pp. 63-97.

Allan, G.J., Bryden, I., McGregor, P.G., Stallard, T., Swales, J.K., Turner, K. and Wallace, R. (2008), "Concurrent and legacy economic and environmental impacts from establishing a marine energy sector in Scotland", Energy Policy, vol. 36, pp. 2734-2753.

Allan, G.J., Lecca, P. and Swales, K. (2014), "The impacts of temporary and anticipated tourism spending", Strathclyde Discussion Paper in Economics, No. 14-06.

Armington, P. (1969), "A theory of demand for products distinguished by place of production", International Monetary Fund Staff Papers, vol. XVI, pp. 159-178.

Arrow, K. J., Chenery, H. B., Minhas, B. S., and Solow, R. M. (1961), "Capital-labor substitution and economic efficiency", The Review of Economics and Statistics, vol. 43, pp. 225-250.

Barro,R.J. and Sala-i-Martin, X. (2004), Economic Growth, $2^{\text {nd }}$ edition, MIT Press, Cambridge Massachusetts.

Blake, A. (2005), "The economic impact of the London 2012 Olympics", TTRI Discussion Paper No. 2005/5, University of Nottingham.

Blake, A. (2009), "The dynamics of tourism's economic impact", Tourism Economics, vol. 15, pp. 615-628.

Blake, A., Durbarry, R., Eugenio-Martin, J.L., Gooroochurn, N., Hay, B., Lennon, J., Sinclair, M.T. Sugiyarto, G. and Yeoman, I. (2006), Integrating forecasting and CGE models: The case of tourism in Scotland, Tourism Management, vol. 27, pp. 292-305.

Blake, A. and Sinclair, M.T. (2003), "Tourism crises management: US response to September 2001", Annals of Tourism Research, vol. 30, pp. 813-832.

Blake, A., Sinclair, M. T. and Sugiyarto, G. (2003), "Quantifying the impact of foot and mouth disease on tourism and the UK economy", Tourism Economics, vol. 9, pp. 449-465.

Bohlmann, H.R. and Van Heerden, J.H. (2005), "The Impact of Hosting a Major Sporting Event on the South African Economy", Journal of Tourism, vol. 26, pp. 595-603. 
Bohlmann, H.R. and Van Heerden, J.H.(2008), "Predicting the economic impact of the 2010 FIFA World Cup on South Africa, International Journal of Sport Management and Marketing, vol. 3, pp. 383-396.

Burgan B. and Mules, T. (1992), "Economic impact of sporting events", Annals of Tourism Research, vol. 19, pp. 700-710.

Cazcarro, I., Hoekstra, A.Y. and Sanchez Choliz, J. (2014), "The water footprint of tourism in Spain", Tourism Management, vol. 40, pp. 90-101.

Daniels, M., Norman, W.C. and Henry, M.S. (2004), "Estimating income effects of a sport tourism event", Annals of Tourism Research, vol. 31 (1), pp. 180-199.

Dwyer, L., Forsyth, P., Madden, J. and Spurr, R. (2000), "Economic impacts of inbound tourism under different assumptions regarding the macroeconomy", Current Issues in Tourism, vol. 3, pp. 325-363.

Dwyer, L., Forsyth, P. and Spurr, R. (2004), “Evaluating tourism's economic effects: new and old approaches", Tourism Management, vol. 25, pp. 307-317.

Dwyer, L., Forsyth, P. and Spurr, R. (2006), "Economic evaluation of special events", Chapter 15 in Dwyer, L. and Forsyth, P. (eds.), International Handbook on the Economics of Tourism, Edward Elgar, Cheltenham, UK.

Eisner R. and Strotz, R. H. (1963), Determinant of Business Investment. Impact of Monetary Policy, Commission on Money and Credit, New Jersey. Prentice-Hall.

Emonts-Holley, T., Ross, A. and Swales, J.K. (2015), "Type II errors in IO multipliers", Strathclyde Discussion Paper in Economics, No. 15-04.

Fletcher, J.E. (1989). "Input-output analysis and tourism impact studies", Annals of Tourism Research, vol. 16, pp. 514-529.

Fourie, J. and Santana-Gallego, M. (2011), "The impact of mega-sport events on tourist arrivals", Tourism Management, vol. 32, pp. 1364-1370.

Gartner, W.C. and Holecek, D.F. (1983), "Economic impact of an annual tourism industry exposition", Annals of Tourism Research, vol. 10, pp. 199-212.

Giesecke J.A. and Madden, J.R. (2011), "Modelling the economic impacts of the Sydney Olympics in retrospect - Game over for the bonanza story?", Economic Papers, vol. 30, pp. 119-287.

Gilmartin, M. and Allan, G.J. (2015), "Regional employment impacts of marine energy in the Scottish economy: A general equilibrium approach", Regional Studies, Vol. 49, pp. 337-355. 
H.M. Treasury (2003), The Green Book: appraisal and evaluation in central government, TSO, London.

Incera, A.C. and Fernández, M.F. (2015), "Tourism and income distribution: Evidence from a developed regional economy", Tourism Management, vol. 48, pp.11-20.

Jorgenson D. W. (1963), "Capital theory and investment behaviour", American Economic Review, vol. 53, pp. 247-259.

Kuper, S. (2014), “Faded glory”, Financial Times, 1 February, 2014, p. 9.

Layard, R., Nickell, S. and Jackman, R. (1991), Unemployment: Macroeconomic Performance and the Labour Market, Oxford University Press, Oxford.

Lecca, P., McGregor, P.G. and Swales, J.K. (2013), "Forward-looking and myopic regional Computable General Equilibrium models: How significant is the distinction?", Economic Modelling, vol. 31, pp. 160-176.

Lee, C. \& Taylor, T.L. (2005), "Critical reflections on the economic impact assessment of a mega-event: the case of 2002 FIFA World Cup', Tourism Management, vol. 26, pp. 595-603.

Li, S. and Blake, A. (2009), "Estimating Olympic-related investment and expenditure", International Journal of Tourism Research, vol. 11, pp. 337-356.

Li, S., Blake, A. and Thomas, R. (2013), "Modelling the economic impact of sports events: The case of the Beijing Olympics", Economic Modelling, vol. 30, pp. 235-244.

McGregor, P.G., J.K. Swales and Y.P., Yin, (1996)," A Long-run Interpretation of Regional InputOutput Analysis", Journal of Regional Science, vol. 36, No. 3, pp. 479-501.

Miller, R.E. and Blair, P.D. (2009), Input-Output Analysis: Foundations and Extensions, $2^{\text {nd }}$ edition, Cambridge University Press, Cambridge.

Munday, M., Turner, K. and Jones, C. (2013), "Accounting for the carbon associated with regional tourism consumption", Tourism Management, vol. 36, pp. 35-44.

Romero, I. and Tejeda, P. (2011), "A multi-level approach to the study of production chains in the tourism sector", Tourism Management, vol. 32, pp. 297-306.

Rose, A.R. and Spiegel, M.K. (2011), "The Olympic effect", The Economic Journal, Vol. 121, p. 652-677.

Round, J. (2003), "Social Accounting Matrices and SAM-based Multiplier Analysis", Chapter 14 in L. A. Pereira da Silva and F. Bourguignon (eds) Techniques for Evaluating the Poverty Impact of Economic Policies, World Bank and Oxford University Press, Oxford. 
Scottish Government (2013), Input-Output Tables and Multipliers 2009, Scottish Government, Edinburgh

Scottish Government Social Research (2014), "An evaluation of legacy from the Glasgow 2014 Commonwealth Games: Pre-games report", Scottish Government Social Research, $28^{\text {th }}$ April 2014, available online at http://www.scotland.gov.uk/Resource/0044/00449344.pdf

TNS, Steer Davies Gleave and Optimal Economics (2014), "XX Commonwealth Games visitor impact study: Interim report", commissioned by Scottish Government, Glasgow City Council, Glasgow Life and Glasgow City Marketing Bureau, November 2014, available online at http://www.gov.scot/Resource/0046/00463511.pdf

Tobin, J. (1969), "A general equilibrium approach to monetary theory", Journal of Money, Credit and Banking, vol. 1, pp. 15-29.

Wagner, J.E. (1997), "Estimating economic impacts from tourism", Annals of Tourism Research, vol. 24, pp. 592-608.

Yeoman, I., Lennon, J.J., Blake, A., Galt, M., Greenwood, C. and McMahon-Beattie, U. (2007), "Oil depletion: What does it mean for Scottish tourism?", Tourism Management, vol. 28, pp. 1354-1365.

Zhou, D., Yanagida, J.F., Chakravorty, U. and Leung, P-S. (1997), "Estimating the economic effects of tourism", Annals of Tourism Research, vol. 24, pp. 76-89. 